\title{
GELENEKSEL HALK TIYATROSUNDA GAYRIMÜSLIMLERIN \\ TEMSiLi
}

özet

Bu çalıșma Osmanlı Imparatorluğu'nun toplumsal örgütlenme yapısını olușturan Millet Sistemi bağlamında Karagöz oyunlarında gayrimüslim Osmanlıların nasıl temsil edildiğini analiz etmeye çalıșmaktadır. Arnavut, Rum, Ermeni, Yahudi, Arap, Türk ve bu kozmopolit yapının diğer unsurları hayal perdesinde zaman zaman oldukça sert, alaycı, hatta bazı görüșlere göre "așağılayıcı" taklitlerle gelmelerine karșın hiçbir zaman birinin bir diğerine göre daha fazla olumlandığını ya da belirli bir dinse/letnik kimliğe yönelik genel bir nefretin söz konusu olduğunu ileri sürmek güçtür. Bu çalıșmada amaçlanan dönemin önemli popüler kültür öğesi olarak Karagöz oyunlarında gayrimüslim Osmanlıların nasıl temsil edildiğini, Millet Sistemi'nin yarattığı görece huzur ortamının bu oyunlara nasıl yansıdığını, taklitlerde bir "ötekileștirme" düșüncesinin var olup olmadığını sorgulamak olacaktır.

\begin{abstract}
This paper aims to analyze how the non muslim Ottomans are represented in Karagöz Plays in accordance with the social system of Ottoman Empire called Millet Sistemi. Rum, Armenian, Arab, Türk, etc. all elements of the cosmopolitan Ottoman Empire, are reflected on curtain comperatively rigourus, sarcastic and in some respects "injurios" representation. However it is clearly seen that the discourse of the plays concede an advantage to none of those etnical and religıos identities. This paper tries to compare the harmonic ensemble reflected in Karagöz plays with Ottoman social order and to reveal the dynamics of all-embrancing and peaceful traits of Karagöz Plays..
\end{abstract}

\author{
REPRESENTATION \\ OF NON-MusLIM \\ OTTOMANS IN \\ TRADITIONAL FOLK \\ THEATREE
}

NilgüN
FiridiNOĞLU*

* Araș.Gör.,Istanbul Üniversitesi, Edebiyat Fakültesi, Tiyatro

Eleștirmenliği ve Dramaturji Bölümü 


\author{
${ }^{1}$ Baskın Oran, Türkiye'de \\ Azınlıklar: Kavramlar, \\ Teori, Lozan, İç Mevzuat, \\ İçtihat, Uygulama (İstanbul: \\ İletișim Yay. 2005), s.105.
}

$\mathrm{H}$ anedan tarafından tanınmıș dört milleti (Milel-i Erbaa), Müslüman Milleti, Ermeni Milleti, Rum Milleti ve Yahudi Milletini kapsayan bu yönetim sistemi içerisinde kușkusuz Müslüman Milleti Millet-i Hakime olarak isimlendirilirken, teșrifatta Rum milletinden sonra üçüncü sırada gelen Ermeni Milleti ise Millet-i Sadıka olarak nitelendirilmekte idi. Gayrimüslim Osmanlılar Millet-i Hakime'nin altında ikinci sınıf vatandaș iseler de Baskın Oran'ın da ifade ettiği gibi "her türlü dinsel, dilsel ve etnik vb gruplar için kültürel haklar (dilini kullanmak, öğretmek, dinsel özgürlükler, vb.) serbestti. Devlet kimin ne konușup yazdığına ve öğrettiğine, ne tür bir dinsel uygulama yaptığına karıșmazdı. Bireye karıșmaz, onun denetimini cemaatlere bırakırdı. O kadar ki, özellikle İstanbul'daki kimi Rumlar kimi zaman Türkçe öğrenmeden ölürlerdi."”

Millet Sistemi kapsamında gayrimüslim bireylerin günlük yașamlarına ilișkin faaliyetlerini idari, mali, medeni alandaki sorumlulukları, kendi cemaatlerine ve yetke sahibi olarak millet bașına (haham ya da patrik) karșı idi. Devletçe muhatap alınan cemaat ve cemaatin lideri oluyordu. Tanzimat Fermanı ve devamındaki

${ }^{2}$ Kemal H. Karpat, Christians and Jews in the Ottoman empire : the functioning of a plural society / edited by Benjamin Braude and Bernard Lewis.(New York : Holmes \& Meier Publishers, 1982.) içinde "Millets and Nationality: The Roots of the incongruity of Nation and State in PostOttoman Era" düzenlemelere ilk karșı tepkilerin öncelikli olarak bahsi geçen cemaat liderlerinden gelmesi bu bağlamda manidardır; devleti laikleștirmeye yönelik reformlar, milletlerin dini kimlikli liderlerinin yetkilerini azaltıyor, devletin bireyleri muhatap almasını öngörüyordu. Sonuç olarak Millet sistemi inancın evrenselliğini vurguluyor ve etnik dilbilimsel farklılıkları yıkmadan onların yerini alıyordu. Osmanlı devletinin politikaları cemaatin sosyal ve ekonomik yașamlarını son derece etkilerken kültürel ve dinsel hayatlarını değiștirmemiștir. ${ }^{2}$

Geleneksel halk tiyatrosu yukarıda genel hatlarıyla bahsettiğimiz millet sistemi organizasyonunun ve imparatorluğun kozmopolit yapısının perdedeki yansımasıdır adeta. Rum, Ermeni, Yahudi, Kürt, Frenk, Türk, Laz, Arap, Arnavut imparatorluğu olușturan tüm etnik ve dini unsurlar hayal perdesinde ya da ortaoyunu meydanında karșımıza çıkar.

Sevinç Sokullu'nun Karagöz oyunlarında "perdeye insanın yansı- 


\section{GELENEKSEL HALK TIYATROSUNDA GAYRIMÜSLIMLERIN TEMSILi}

madığı”’3 șeklindeki tespiti bu bağlamda oldukça yerindedir. Bu oyunlardaki tipler Osmanlı İmparatorluğu içerisinde yașayan davranıș özellikleri, konușma tarzı, șive özellikleriyle belli bir cemaati yansıtan kalıplașmıș tiplerdir.

Bu tiplerin temsilinde ( özellikle erken dönemlere, örneğin on sekizinci yüzyıla tarihlenen metinlerde ) özel isimlere yer verilmemesi imparatorluğun yönetim pratiğinin olduğu kadar insanların birbirleriyle kurduğu ilișkinin de cemaatler üzerinden gerçekleștiğinin bir göstergesi niteliğindedir. Dolayısıyla bu tipler ait oldukları milletin ya da cemaatin kültürel, dinsel, sosyal, farklıııklarını üzerlerinde barındıran gölge kișiler olarak perdeye yansırlar. Karagöz oyunlarındaki bu niteleme sadece gayrimüslim tiplere özgü değildir. Arap, Arnavut, Acem, Laz, Rumelili gibi çeșitli açılardan (dilsel, kültürel) azınlık sayılabilecek Müslüman tebaa da yine cemaat-aidiyet ilișkisi çerçevesinde mensup oldukları topluluğa göre perdeye buyur edilirler. İmparatorluğun kozmopolit birlikteliğini yansıtan geleneksel halk tiyatrosu örneklerinde oyun figürlerinin birbirleriyle olan ilișkilerinde birbirleriyle söyleșmelerinde herhangi bir dini ya da etnik mensubiyeti hedef alan așağılamanın varlığından söz etmek mümkün değildir. Bu durum hiç kușkusuz Osmanlı İmparatorluğu'nun, etnikliği siyasi bir etmen olarak etkisiz hale getiren bir politika izlemiș olmasına bağlanabilir. ${ }^{4}$ Etnik kimliğin politik olarak etkinleștirilmediğinin kușkusuz en iyi örneği geleneksel halk tiyatrosunda kültürel ve dinsel özellikleriyle özdeșleștirilerek temsil edilen taklitlerdir. Yavuz Pekman Geleneksel Türk Tiyatrosu'nun etnik kimliklere karșı tavrını șöyle açıklamaktadır:

"Geleneksel tiyatro herhangi bir etnik grubu merkeze almadığından, tüm șaka, eleștiri, alaysama ve tașlamalarında, herkese eșit mesafe ile yaklașır." 5

Bu tiplerin temsilinde ( özellikle erken dönemlere, örneğin on sekizinci yüzyıla tarihlenen metinlerde ) özel isimlere yer verilmemesi imparatorluğun yönetim pratiğinin olduğu kadar insanların birbirleriyle kurduğu ilișkinin de cemaatler üzerinden gerçekleștiğinin bir göstergesi niteliğindedir. Dolayısıyla bu tipler ait oldukları milletin ya da cemaatin kültürel, dinsel, sosyal, farklılıkları-
${ }^{3}$ Sevinç Sokullu, Türk

Tiyatrosunda Komedyanın

Evrimi (Ankara: Kültür Bakanlığı

Yayınları, 1978), s. 142.

\author{
4 Kemal Karpat, Osmanlı'da \\ Değișim, Modernleșme ve \\ Uluslașma. Çev. Dilek Özdemir. \\ (Ankara: İmge Kitabevi, 2006), \\ s. 273. \\ 5 Yavuz Pekman, Çağdaș Türk \\ Tiyatromuzda Geleneksellik \\ (Istanbul: MitosBoyut Yay., \\ 2002), s. 56.
}


6 Aynı, s.56.

7 Cevdet Kudret, Karagöz Cilt 3 (Ankara: Bilgi Yay. 1970), s. 400. nı üzerlerinde barındıran gölge kișiler olarak perdeye yansırlar. Karagöz oyunlarındaki bu niteleme sadece gayrimüslim tiplere özgü değildir. Arap, Arnavut, Acem, Laz, Rumelili gibi çeșitli açılardan (dilsel, kültürel) azınlık sayılabilecek Müslüman tebaa da yine cemaat-aidiyet ilișkisi çerçevesinde mensup oldukları topluluğa göre perdeye buyur edilirler. İmparatorluğun kozmopolit birlikteliğini yansıtan geleneksel halk tiyatrosu örneklerinde oyun figürlerinin birbirleriyle olan ilișkilerinde birbirleriyle söyleșmelerinde herhangi bir dini ya da etnik mensubiyeti hedef alan așağılamanın varlığından söz etmek mümkün değildir. Bu durum hiç kușkusuz Osmanlı İmparatorluğu'nun, etnikliği siyasi bir etmen olarak etkisiz hale getiren bir politika izlemiș olmasına bağlanabilir. Etnik kimliğin politik olarak etkinleștirilmediğinin kușkusuz en iyi örneği geleneksel halk tiyatrosunda kültürel ve dinsel özellikleriyle özdeșleștirilerek temsil edilen taklitlerdir. Yavuz Pekman Geleneksel Türk Tiyatrosu'nun etnik kimliklere karșı tavrını șöyle açıklamaktadır:

"Geleneksel tiyatro herhangi bir etnik grubu merkeze almadığından, tüm șaka, eleștiri, alaysama ve tașlamalarında, herkese eșit mesafe ile yaklașır."

Yazıcı adlı Karagöz oyununda Türk ve Karagöz arasında geçen așağıdaki söyleșme bu bakımdan oldukça manidardır.

Karagöz- Hoș geldin gözüm.

Türk- Gözün çıksın.

Karagöz- Behey ciğerim!

Türk- Ciğerini gopegler yisün!

Karagöz- Behey Canım!

Türk- Canın çıksın!

Karagöz- Behey ayı!

Türk- Merhaba dayu!

Osmanlı sosyal ve politik örgütlenmesi ile geleneksel halk tiyatrosunun etnik kimliklere yaklașımı arasındaki paralellik açıķa görülmektedir. Samim Akgönül'ün Osmanlı egemen sınıfı için etnik aidiyetin önemini ve bu sınıfın etnik kimliklere karșı tavrını dile getirdiği așağıdaki değerlendirmesi bu paralelliği pekiștir- 
mesi bakımından oldukça önemlidir:

Egemen grup kelimenin modern anlamıla etnik olarak egemen değildir. İmparatorluğu kuran bu grubun kahramanlık özelliklerine ve Türk kökenlerine değer verdiği doğrudur. Ancak gerçeklere baktığımızda, yokluk içindeki köylülerle ya da kaba göçebelerle aynı kefeye konulan "Türk" grubun saygınlık merdiveninin en alt basamaklarında yer aldığı görülmektedir. $^{8}$

Ancak unutulmamalıdır ki Osmanlı İmparatorluğu'nda etnik kimlik politik olarak etkinleștirilmezken tebaa olarak kabul edilmenin șartı etkinleștirilen dini aidiyettir. Roderic Davison'a göre milletlerin özerk yapılanması Müslümanlarca ve yönetici sınıf tarafından gayrimüslimlerin ikinci sınıf vatandaș olarak konumlandırımalarına engel değildi. ${ }^{9}$ Her ne kadar kendi içinde özerk denilebilecek bir yapının unsurları olsalar da Ermeni, Rum, Yahudi milleti hâkim mahkûm millet ikiliğinin mahkûm parçalarıydılar. Etkinleștirilen dini aidiyet ve olușturulan Millet sistemi uygulamaları çerçevesinde hâkim milletin yani Müslüman tebaanın hassasiyetleri ön planda tutularak klasik dönemden itibaren gayrimüslimler ile Müslümanların mahalleleri, okulları, sosyal alanlarda birbirlerinden ayrıștırılmaya yönelik bir takım uygulamalar söz konusudur. Bu bağlamda geleneksel halk tiyatrosunun egemen grubun hassasiyetlerinin dıșında bir birliktelik olușturduğunu söylemek mümkündür.

Geleneksel halk tiyatrosunda etnik köken gibi herhangi bir dinsel inancının da merkezde olduğunu söylemek, Müslümanlık inancına bir ayrıcalık ve dokunulmazlık atfedildiğinden bahsetmek oyunlara baktığımızda pek mümkün görünmemektedir. Salıncak oyununda salıncaktan düșerek ölen Yahudi'nin arkasından yapılan ayinde Hahambașı, havyar salatası, turp salatası, soğan salatasından bahsederken Yahudi cemaat bu duaya âmin diyerek karșilık verir. Benzer bir biçimde Ortaklar adlı oyunda Karagöz'ün nikâhını kıyacak olan imamın duası çifte semerli damattan, kocalarının bașını yiyen gelinden bahseden, çiftin soylarının soplarının belirsizliğini konu alan ve cemaatin uyumla amin

\footnotetext{
${ }^{8}$ Samim Akgönül, Türkiye Rumları Ulus Devlet Çağından Küreselleșme Çağına Bir Azınlığın Yok Olus Süreci (İstanbul: İletișim Yay., 2007), s. 38 .
}

\footnotetext{
${ }^{9}$ Roderic H. Davison, Osmanlı Türk Tarihi (1774-1923) (İstanbul: Alkım Yayınevi, 2004), s.166.
} 
dediği gayet magazinsel bir duadır.

10 Kemal Karpat, a.g.e., s. 260.
Tüm Osmanlı tebaasının herhangi bir ayrıștırmaya tabi tutulmaksızın geleneksel halk tiyatrosunda ve özellikle Karagöz oyunlarında bir araya gelmelerini sağlayan bir bașka önemli unsur taklitlerin imparatorluğun örgütlenme yapısı içerisinde ayrıcalıklı statüsü olmayan figürlerden olușmasıdır. Kemal Karpat' a göre Osmanlı örgütlenme yapısı içerisinde ayrıcalıklı statüyü belirleyen devletle kurulan ilișki ve devlete yapılan hizmetti; toplum içindeki gerçek mevkiiyi, sosyal statüyü ve itibarı inanç değil hükümetle bağlantılı olmak belirlemekteydi. ${ }^{10}$

Karpat'ın bu tespitleri ıșığında geleneksel halk tiyatrosunun kiși kadrolarında baktığımızda hanedandaki egemen sınıfa hizmet eden asker, memur, mültezim vb. hiçbir tiplemenin yer almaması oldukça manidardır. Üstünlüğün devlete hizmetle belirlendiği bu yapılanma içerisinde geleneksel halk tiyatrosunun ayrıcalıklı gruplara karșı bu dıșlayıcı tavrı her kimlikten tiplerin kendi geçici üstünlüklerini yaratmalarına neden olmaktadır. Dolayısıyla egemenlerden arındırımıș bu oyunlarda ezilenlerin ortaklıkları onların birbirleriyle kurdukları sıcak ilișkinin birbirlerine karșı gösterdikleri hoșgörünün belki de en önemli nedenidir.

Geleneksel halk tiyatrosu örneklerinde hâkim tonun ne bu karma sınıf mensuplarından birinde ne de belirli bir dini ya da etnik aidiyetin tekelinde olmayıșı oyunlarda karșılaștığımız en acımasız alayda bile düșmanca bir tavrın bulunmamasının nedeni olarak düșünülebilinir.

Unutmamak gerekir ki geleneksel halk tiyatrosunda azarlayan, dalga geçen sadece Karagöz gibi eksen kișiler değildir, yüksek bir güven duygusu ve bazen karagöze neler oluyor, sorusunu akla getirecek kadar güçlü karșı atakları ile gayrimüslimleri de görürüz. Bu durumu, Salıncak oyununda Karagöz ve Yahudi arasında geçen söyleșme ile örneklendirebiliriz: 


$\begin{array}{ll}\text { Yahudi } & \text { Kaç para vereceğiz sallamak için } \\ \text { Karagöz } & \text { Yüz kuruș } \\ \text { Yahudi } & \text { Vay kademsiz oğlu kademsiz sen de ka- } \\ & \text { rın da beraber mi? }\end{array}$

Karagöz

\begin{abstract}
Doğru konuș Yahudi teperim șimdi seni!
\end{abstract}
Geleneksel halk tiyatrosunda toplumsal normlara göre "kötü" ya da "ahlak dıșı" olan tüm özelliklerin dengeli bir biçimde taklitler üzerinden yansıtılmaktadır. İstenmeyen, toplumsal normların kabul etmediği insan davranıșları herhangi bir cemaatin üzerine yığılmaz. Bu duruma örnek olarak cimri Yahudi, kaba saba Türk, cahil Karagöz, gibi birçok dengeli ikilik sayılabilir.

Karagöz oyunlarında genellikle hafifmeșrep, entrikacı kadın olarak çizilen Zenne tipinin çoğunlukla dini ya da etnik kimliğinin vurgulanmıyor olması bu bağlamda dikkat çekicidir. Birkaç nadir örnek dișında Zenne tipinin direkt olarak bir cemaate gönderme yapacak onu anıștıracak bir isimle taklit edilmediğini görebiliriz. Salkıminci, Mercan gibi herhangi bir etnik ya da dinsel cemaate ait olabilecek isimlerle anılan kadın tiplerin bu aidiyetsizlikleri kușkusuz Tanzimat dönemi Türk edebiyatını ve tiyatro edebiyatını düșündüğümüzde oldukça önemlidir. Yüzeysel batıııașmanın beraberinde ahlaki yozlașmayı da getirdiği yönündeki hâkim görüș bu dönem yazarlarının kötü kadın imajını genellikle gayrimüslim kadınlar üzerinden yaratmalarına neden olmuștur.

İmparatorluğu olușturan tüm unsurların birlikte ve barıș içerisinde yașamlarını yansılayan ve hatta kimi zaman egemen grubun hassasiyetlerini de hiçe sayabilen geleneksel halk tiyatrosunun bu bağlamda önemini daha iyi anlamak için Tanzimat ve Meșrutiyet dönemi tiyatro edebiyatından bir kaç örneği ele almak fikir açıcı olacaktır. Kușkusuz Avrupa'nın artan askeri, ekonomik ve politik nüfuzu Osmanlı devletinin geleneksel etnik politikalarından vazgeçerek etniklik üzerinde olușturulmuș Avrupa politik yapılanma sistemini benimsemesine neden olmuș ve 1454'den beri devletin yönetim ve organizasyonunun temelini olușturan Millet Sistemi geleneğinin de kademeli olarak tasfiyesini gerekli kılmıștır. ${ }^{11}$ Milliyetçilik fikirlerinin Tanzimat ile birlikte șekillenme-
* İstanbul'un 1453 yılında fethinden sonra Sultan II. Mehmet, Rum, Yahudi ve Ermeni milletlerine, yani imparatorluğun dini anlamda tanımlamıș topluluklarına, sırasıyla o zaman Yunan Ortodoks Kilisesi'nin Patriği Genadios (1454) Ermeni Kilisesi'nin Piskoposu (1461) ve Joachim Bașhaham Moses Capsali vasıtalarıyla geniș özerklik bahșetmiștir. Bkz. Christians and Jews in the Ottoman Empire : The functioning of a plural society / by Benjamin Braude and Bernard Lewis. New York : Holmes \& Meier Publishers,1982. 
ye bașlaması neticesinde geleneksel halk tiyatrosu ile 1839 sonrasında üretilen tiyatro metinlerinde yerel kültürlerin ve farklı dini inançlara sahip cemaatlerin ele alıș biçimi arasında ortaya çıkan farklılıkları gözlemlemek mümkündür.

Yukarıda kısaca bahsettiğimiz Karagöz'deki zenne tipinin dini, etnik kökeninden bağımsız olarak temsiline karșı Tanzimat dönemi Türk edebiyatında ve sonrasında kötü yola düșen, hafifmeșrep, kötü ahlaklı kadınların genellikle gayrimüslim oldukları gerçeği bile farklılașmayı ortaya koyar niteliktedirSevinç Sokullu'nun "Yergisel gülünçlemenin acımasız ve düșmanca niteliğine Karagöz'de olduğu gibi Ortaoyunu'nda da rastlanmaz. Alayda eleștiri ve șamata egemendir." ${ }^{12}$ șeklindeki tespitine gayrimüslim Osmanlıların temsili özelinde baktığımızda Tanzimat sonrası yazılan oyunlarda bu değerlendirmenin yavaș yavaș ortadan kalktığını görmek mümkündür. Alay ve șamata kademeli olarak ortadan kalkarken yerini "biz ve onlar" kutuplașması bağlamında ciddi eleștirilere bırakmıștır. Hatta kimi tiyatro oyunlarında bu çok kültürlü yapı tamamen ve birdenbire ortadan kaldırımıștır.

Türk tiyatro edebiyatının kanonunda yer alan İbrahim Șinasi'nin Șair Evlenmesi'nde geleneksel Türk tiyatrosuna has dil kullanımı, mekân kullanımı, gibi bir takım yapısal özelliklerin izleri sürülürken , aynı oyunda çok kültürlü kozmopolit yapının bir hayli uzağında bir șahıs kadrosuna rastlanır.

Benzer bir șekilde Vatan yahut Silistre'de Namık Kemal, İslam Bey'in vatanı kurtaracak gücün sadece Müslüman Osmanlıların elinde olduğunu ve hatta Müslüman Osmanlıların görevi olduğunu ileri sürerken vatanın sahiplerini ve Osmanlı kimliğini tanımlar. İlber Ortaylı'nın altını çizdiği gibi Namık Kemal'in "Osmanlısı" oyunda da görüldüğü üzere imparatorluğun gayrimüslim unsurlarını dıșlayan Müslüman bir Osmanlııktır.

Safveti Ziya'nın 1912'de yazdığı Haralambos Cankiyadis'de esere adını veren Rum sarraf, imparatorluğun içinde bulunduğu ekonomik dar boğaz nedeniyle geçinemeyen memurların, maașlarını 


\section{GELENEKSEL HALK TIYATROSUNDA GAYRIMÜSLIMLERIN TEMSILi}

kırdırdıkları, maliye nazııını, pașaları elinde oynatan bir tefeci olarak çizilir. Manastırlı Mehmet Rıfat'ın Görenek adlı oyununda da ev ev dolașan bohçacı Ermeni kadın Manik Dudu, Müslüman Osmanlı köșk sakinlerinden dar zamanlarında mücevherlerini ucuza kapatarak alır. Osmanlı'yı, Avrupa'nın "hasta adamını" kendi sinesinden yapılan ihanetlerin bir daha iyileștiremediği hususundaki ön kabulün yansıması olarak "arkadan vurma", "en zayıf anında vurma", "ihanet” vb. gibi genel izleklerin farklı kurgularla bu dönem yazılan oyunlarda tekrarlandığını görebiliriz.

Bu kısa karșılaștırmanın ardından son olarak tekrar geleneksel halk tiyatrosuna baktığımızda etnik ya da dini, cemaatler arasında çatıșmanın olmadığı, egemen söylemler ya da sınıflandırmaların çok uzağında bir birliktelik hukuku olușturan, hiyerarșilerin yıkıldığı bir alan karșımıza çıkar. Halk tiyatrosu dini ya da etnik aidiyetin kimseyi ayrıcalıklı kılmadığı, hiçbir aidiyetin Karagöz'ün dayağından kurtulmak için yeterli olmadığı bir dünya sunar.

\section{KAYNAKÇA}

Akgönül, Samim. Türkiye Rumları "Ulus Devlet Çağından Küreselleșme Çağına Bir Azını̆̆ın Yok Oluș Süreci”. İstanbul: Iletișim Yayınları, 2007.

Braude Benjamin and Bernard Lewis (Ed.). Christians and Jews in the Ottoman Empire: The functioning of a pluralsociety / edited by. New York: Holmes \& Meier Publishers, 1982

Davison, Roderic H. Osmanlı Türk Tarihi (1774-1923). Istanbul: Alkım Yayınevi, 2004.

Güzel Hasan Celâl (Ed.). Osmanlı'dan Günümüze Ermeni Sorunu. Ankara: Yeni Türkiye Yayınları, 2001.

Karpat, Kemal H. Osmanlı'da Değișim, Modernleșme ve Uluslașma, Çev. Dilek Özdemir, Ankara: Imge Kitabevi, 2006.

Kudret, Cevdet; Karagöz, v.1.2.3. Ankara: Bilgi Yay. 1970.

Oran, Baskın; Türkiye'de Azınlıklar: Kavramlar, Lozan, İç mevzuat, Içtihat,Uygulama. İstanbul: Iletișim Yayınları, 2005.

Ortaylı, IIlber. Osmanlı Barıșı, İstanbul: Timaș Yayınları, 2007.

Pekman, Yavuz. Çağdaș Türk Tiyatromuzda Geleneksellik, İstanbul: MitosBoyut Yayınları, 2002.

Sokullu,Sevinç. Türk Tiyatrosunda Komedyanın Evrimi, Ankara: Kültür Bakanlığı Yayınları, 1978.

$$
\text { बैंือ }
$$


